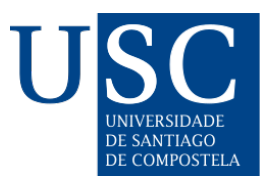

\title{
Seguridad y Derecho: Principales desafíos a debate
}

\section{Christian Griot Pérez}

Grupo de Investigación sobre Políticas Públicas, Seguridad Internacional y Gobernanza Global Universidad Europea de Madrid, España

cgriot1103@gmail.com

El libro titulado Seguridad y Derecho: Principales desafíos a debate, propone una lectura que marca los distintos desafíos que tiene el derecho y la seguridad en las sociedades democráticas. Los coordinadores Julia Pulido Gragera y Daniel Sansó - Rubert Pascual, junto a los autores Esther Alba Ferré, Lidia Moreno Blesa, Natalia Del Barrio, José Julio Fernández Rodríguez, Carmen Florit Fernández, Elena García - Antón Palacios, Rubén Herrero Giménez, María José Molina García y David Pavón Herradón, desarrollaron esta obra colectiva.

Publicación, que logra abordar con profundidad analítica los grandes temas esenciales para la seguridad y defensa en el contexto global, necesarios para la compresión de la actualidad que busca generar un debate sobre cuáles son los mecanismos que deben adoptar las instituciones para poder combatir las nuevas amenazas. El terrorismo, es uno de los mayores problemas para los Estados. Ponderar y replantear nuevas políticas constituyen un reto para los organismos gubernamentales, que deben transmitir un sentimiento de seguridad en la ciudadanía. El respeto de los Derechos Fundamentales es esencial para dotar de legalidad y legitimidad estas nuevas acciones de lucha contra el terrorismo, por consiguiente, las autoras Esther Alba Ferré y Lidia Moreno Blesa platean el siguiente tema, "la posible inclusión de la pérdida de la nacionalidad adquirida de los terroristas españoles siempre respetando el marco constitucional ". El capítulo refleja un análisis que nos permite entrar en contexto con la situación nacional en España, a través de su legislación y sentencias emitidas, y por otra parte en el ámbito regional con los vecinos europeos.

La Unión Europea ha emitido una serie de medidas de lucha contra el terrorismo como la intensificación en los controles fronterizos y mayor control de armas de fuego. Si es verdad que algunos estados han tomado decisiones nacionales que podrían tener mayor impacto, como es el caso de Alemania, que reformo la ley extranjería para poder agilizar la expulsión de extranjeros condenados e inmigrantes sin permisos de residencias. Bélgica modifico el Código de Nacionalidad para que los condenados con doble nacionalidad por penas mayores de cinco años por delitos contra la seguridad del Estado, se les retirara la nacionalidad belga. La legislación francesa permite la privación de la nacionalidad adquirida en los últimos15 años por delitos graves como el terrorismo, solo en el caso de tener la doble nacionalidad. En España la nacionalidad esta garantizada por su legislación interna y se encuentra regulada en el derecho internacional público a través de los tratados internacionales a los cuales España forma parte, determinando que la privación de la nacionalidad no debe ser arbitraria, pero su regulación interna no considera que la nacionalidad sea un derecho fundamental. La Constitución española reconoce la doble nacionalidad, al igual que 
la distinción entre los españoles de origen, cuya privación de la nacionalidad es inadmitidle. Como se ha indicado en este capítulo, la falta de homogeneidad entre los estados miembros de la Unión Europea no permite que se de una respuesta común a unos de los mayores problemas de seguridad que tiene la región. España por su parte no consigue aprobar una ley que permita la perdida de la nacional por cometer actos terroristas.

Otro de los grandes retos que tienen las sociedades occidentales es la migración, con respecto a los choques culturales que pueden existir entre la población de origen y la inmigrante. La autora Natalia Del Barrio, realiza un análisis profundo entre la libertad religiosa y sus limites en relación con la seguridad. El velo islámico puede originar una controversia como derecho fundamental a la libertad religiosa y el establecimiento del orden público entorno a la seguridad ciudadana. La Constitución española garantiza la libertad religiosa en sus dos dimensiones, en la interna permite que una persona pueda adoptar las creencias religiosas de su elección, esta dimensión internum, no está expuesta a limitaciones y con respecto a la externa agere licere, se refiere a que una persona puede acomodar sus conductas impuesto por sus creencias y esta, si está sometida a limitaciones. El derecho internacional público también permite que se garantice el derecho a la libertad de religión, que puede ser limitado al igual que en la legislación interna, en el foro externo. Estas limitaciones pueden estar argumentadas bajo los conceptos de "orden público “y "seguridad pública ", pero es allí el problema de establecer dichas limitaciones con la dificultad de definir jurídicamente a ambos conceptos. La autora establece la utilización del velo islámico estaría limitado a la forma en que no irrumpa con el orden público. ¿Como un velo puede generar perturbaciones a la seguridad?, para ello se debe analizar el significado jurídico - religioso del hiyab. que realiza la profesora Del Barrio en este capitulo.

La seguridad es un elemento esencial para que los ciudadanos pueden gozar de sus derechos, el mundo percibe ciertos riesgos y amenazas donde los Estados y sus respectivos gobiernos tiene la capacidad de contener dichas amenazas, deben hacerlo bajo el imperio de ley y el respeto de los derechos humanos. El autor José Julio Fernández Rodríguez nos aproxima a su capítulo sobre la seguridad bajo la protección de los derechos fundamentales. La relación entre seguridad y derecho fundamentales es una conexión que se puede medir en dos planos, positiva o negativa, y se supone que a mayor seguridad más goce de derechos fundamentales se puede alcanzar, ambos se retroalimentan y esto permite que los países sean más democráticos. En la actualidad nos movemos en un entorno asimétrico, hibrido y multipolar, que despierta unos nuevos paradigmas en el ámbito de la seguridad y que presupone más dificultad al momento de encontrar soluciones balanceadas en el ámbito jurídico y en el campo del orden público. La limitación externa o extrínseca de los derechos fundamentales, permite tener más control de la seguridad por parte del Estado, que puede exigir esa limitación de manera legitima a través de los procedimientos jurídicos correctos, bajo el principio de proporcionalidad, que estima la limitación de los derechos fundamentales por razones de seguridad y la proporcionalidad deben ser presidida por quien aplica la norma. El autor también describe las posibles situaciones jurídicas de exclusión que permite la suspensión general en aplicación de ciertos derechos y hace referencia al uso de las Fuerzas Armadas como garantistas de la seguridad nacional.

El ciberespacio es la dimensión actual donde los ciudadanos se sientes más vulnerables. La aparición de las redes sociales más la información personal acumulada en las distintas plataformas digitales crea una sensación de desprotección por parte del Estado. La autora Carmen Florit Fernández, nos presenta un capítulo sobre la seguridad de los menores en la red bajo la Ley Orgánica de Protección Jurídica del Menor. El internet se a convertido en un arma de doble filo, 
donde muchos usuarios han decidido vender una imagen de ellos mismo y de sus relativos. Esto implica que la seguridad debe involucrar en la protección de los menores, para que su intimidad, su honor, su propia imagen y sus datos personales no sean utilizados para fines ilícitos. Actualmente la legislación española prevé en cierta parte la protección de los menores, pero se siguen viviendo situaciones donde los menores son las victimas y sufren acoso escolar a través de las plataformas, explotación laboral y abusos sexuales. Dentro de la Ley Orgánica de Protección Jurídica del Menor, se encuentra las mayorías de las regulaciones que protegen en España a los menores de edad, pero que no cubre todos los problemas esencialmente la creación de una huella digital, a causa de proporcionar información a personas desconocidas.

La ciberseguridad a través de la protección de datos cada día tiene retos más grandes, el terrorismo fundamentalista islámico genera desasosiego en los gobiernos europeos por los atentados que se han cometido en los últimos años. La libertad de religión y la seguridad tienen una conexión que es justamente el ciberespacio, una dimensión repleta de datos e información. La autora Elena García - Antón Palacios nos redacta un capítulo que analiza la protección de datos y la libertad religiosa frente a las ciberamenazas de grupos terrorista tomando en cuenta las Estrategia Nacional de Seguridad 2017 y la Estrategia Nacional de Ciberseguridad 2019 en España. Dentro del ordenamiento jurídico español se garantiza la libertad religiosa, y este derecho puede ser limitado en su dimensión externa, cuando es necesario el mantenimiento del orden público. El Estado debe de analizar las situaciones donde los grupos terroristas atenten de manera directa contra el orden público, es ahí donde el derecho a la libertad religiosa se encuentra en posición para ser limitado. El ciberespacio es utilizado por grupos terroristas para accionar su publicidad, propaganda, adoctrinamiento y reclutamiento a través de las distintas plataformas como las redes sociales. Por esto el Estado debe garantizar la protección de datos de sus ciudadanos y que hoy es reconocido como un derecho fundamental. La creación de las dos Estrategias de Seguridad Nacional, han sido una apuesta por la lucha contra el terrorismo en España, en ambos planes de seguridad se aprecia que el desarrollo tecnológico de los grupos terroristas a incrementado, al igual que su capacidad de financiación online y de reclutamiento.

El autor Rubén Herrero Giménez y su capítulo "La grabación realizada por particulares “, donde realiza un análisis sobre conversaciones entre particulares que han sido supuestos de grabación. Las grabaciones en secreto de conversaciones entre interlocutores, cuando son grabadas con el consentimiento de la parte no atacan al derecho al secreto de las comunicaciones y tampoco a la intimidad, en pocas palabras no es secreto, salvo que una de las partes o personas tenga una condición especial profesional como por ejemplo abogado, procurador, personal eclesiástico, etc. Se indica la licitud de grabaciones telefónicas entre particulares si se mantiene de una manera libre, voluntaria y que no sea coaccionada por alguno de los participantes. Las intervenciones de las comunicaciones restringen el derecho al secreto con excepcionalidad, si legalmente esta previsto, una orden judicial y si se realiza con estricta observancia dentro del principio de proporcionalidad. El autor nos coloca en los distintos contextos para observar la legalidad de las grabaciones en el caso de una relación cliente - abogado, un supuesto de grabación con cámara oculta por periodista y en el caso la intervención de una conversación por parte de un detective privado.

La comunidad internacional juega un papel muy importante para alcanzar el objetivo de la paz y seguridad mundial, el mundo de hoy presenta nuevos retos para los Estados y para la cooperación entre ellos, la autora María José Molina García nos plantea en su capítulo la importancia de la seguridad humana como objetivo necesario de la comunidad internacional y como las Naciones Unidas y la Unión Europea deben llevar acabo este cometido. La seguridad humana como concepto, 
lleva evolucionando todos estos años, ya que el panorama contempla nuevas amenazas múltiples, complejas, internacionales y transnacionales. El derecho internacional público establece que la seguridad humana esta equilibrada con la defensa de la soberanía, junto a la protección de los derechos humanos y el desarrollo sostenible, que a través de sus fuentes de derecho como los tratados internacionales, las costumbres, la jurisprudencia y las normas ius cogens, puedan permitir el desenvolvimiento de manera correcta los derechos humanos, el derecho humanitario, derecho penal internacional, el derechos de los refugiados y el derecho ambiental. Las organizaciones internacionales como las Naciones Unidas y La Unión Europea a través de sus órganos han establecido los distintos mecanismos jurídicos dentro del derecho internacional público para hacer eficaz la seguridad humana, pero es necesario la cooperación de los Estados para hacer efectiva esa protección.

En la rama del derecho penal se aspira a amparar ciertos intereses y bienes jurídicos cuando se busca agredir a dichos intereses, el autor David Pavón Herradón examina la protección de la defensa nacional en base al delito de divulgación de inventos objeto de solicitud de patente secreta. El Código Penal integra después de su Libro II la rúbrica "Delitos y sus penas ", donde establece los "delitos relativos a la propiedad intelectual e industrial, al mercado y a los consumidores ", el delito se refiere a la actitud de hacer público de manera intencional una invención objeto de patente secreta, cuando perjudica a la defensa nacional. Se encuentra regulado por el artículo 277 del Código Penal, y debería ser clasificado según el autor no entre los delitos relativos de la propiedad industrial, si no en los delitos de descubrimiento y revelación de secretos e informaciones relativas a la defensa nacional.

La democracia es el mejor sistema de gobierno, una de las grandes características de la democracia es que esta basada en el principio de la representación electa, que dota de capacidad y competencia a los decisores de realizar acciones legitimadas en la voluntad popular. Los servicios de inteligencias son un actor fundamental para el establecimiento de una sociedad segura, su tarea es asesorar y avisar a la cúpula política sobre posibles amenazas que puedan afectar al Estado. Los coordinadores y autores de este capítulo Julia Pulido Gregera y Daniel Sansó - Rubert Pascual, expone sobre el Estado, sus servicios de inteligencia y controles democráticos en España. La actividad de la inteligencia regulada en el ordenamiento jurídico español aporta grandes cantidades de información que permite antecederse, buscar una prevención y actuar a través de la articulación de políticas públicas para proteger los intereses de los españoles. Los servicios de inteligencias forman parte de la Administración Pública que incomodad de cierta manera al Estado a través de sus regulaciones en comparación con otras instituciones en materia de defensa y seguridad. El Centro Nacional de Inteligencia esta sometido a control por parte del Estado, es necesario establecer un control extraordinario e independiente que pueda cumplir con los derechos fundamentales de sus miembros activos y de la ciudadanía. 


\section{Información Adicional:}

Título: Seguridad y Derecho: Principales desafíos a debate

Autor: Julia Pulido Gragera y Daniel Sansó-Rubert Pascual (Coords.)

Editorial: Dykinson

Año de edición: 2020

Páginas: 196

ISBN: 978-84-1324-765-6 